\begin{tabular}{|c|l|}
\hline Title & Effects of team unlearning on employee creativity : The mediating effect of individual reflection \\
\hline Author(s) & Matsuo, Makoto \\
\hline Citation & $\begin{array}{l}\text { Journal of Workplace Learning, 30(7), 531-544 } \\
\text { https://doi.org/L0.1108/JWL-03-20180045 }\end{array}$ \\
\hline Issue Date & 2018 \\
\hline Doc URL & http://hdl.handle.net/2115/72101 \\
\hline Type & article(author version) \\
\hline File Information & Self-archiving_(JWP2018).pdf \\
\hline
\end{tabular}

Instructions for use 


\title{
Effects of team unlearning on employee creativity
}

\section{The mediating effect of individual reflection}

\author{
Makoto Matsuo \\ Graduate School of Economics and Business Administration, \\ Hokkaido University, Sapporo, Japan
}

\begin{abstract}
Purpose - Although unlearning is considered an essential step for creativity, little is known about the relationship between team unlearning and employee creativity. The purpose of this study was to investigate the mediating role of individual reflection between team unlearning and employee creativity.

Design/methodology/approach - The research model was tested using multisource survey data from 164 employees in 28 teams at a manufacturing firm and a service firm. Findings - The results of the multilevel analyses indicated that team unlearning had a positive influence on supervisor-rated employee creativity, fully mediated by individual reflection.

Practical implications - It should be noted that employee creativity is not automatically enhanced through team unlearning. Managers should encourage members to reflect on their work practices following team-unlearning exercises for the purpose of enhancing their creativity.

Originality/value - The findings contribute to the existing literature by demonstrating that reflective practices play significant roles in linking team unlearning with employee creativity. This study explored preceding literature examining employee creativity in terms of the unlearning process.
\end{abstract}

Keywords Employee creativity, Individual reflection, Team unlearning

Paper type Research paper 


\section{Introduction}

Since employee, or individual, creativity is a major contributor to organizational innovation and competitive advantage in dynamic environments (Hirst et al., 2015; Sue-Chan and Hempel, 2016), investigating how to enhance employee creativity is an important aspect of human resource management (HRM) (Clercq et al., 2017; Dul et al., 2011). Amabile and Pillemer (2012) stated that one of the most interesting developments concerns the discovery of team-level creativity-relevant processes in addition to those at the individual-level.

Although previous studies have explored the antecedents of employee creativity in terms of various team-level factors, such as transformational leadership (Gong et al., 2009), team learning (Hirst et al., 2009) and empowering leadership (Zhang and Bartol, 2010), little is known about the effects of team unlearning, defined as the process by which teams consciously choose to give up, abandon or stop relying on particular beliefs and routines (Akgun et al., 2006; Hislop et al., 2014). Team unlearning is important for employee creativity because flexibility with regard to beliefs and routines is an essential trait when producing new and useful ideas (Edmondson et al., 2001; Keskin, 2006). When employees adhere to existing beliefs and work routines, the generation of creative ideas is impeded (Farh et al., 2010; Wang and Ahmed, 2003).

However, team unlearning may not automatically promote members' creativity, because individuals need to rethink their own specific work processes to acquire knowledge and produce new ideas (Boud, Cressery and Docherty, 2006; Kolb, 1984; Schön, 1983). Thus, this study incorporated individual reflection as a mediating factor between team unlearning and employee creativity. It is surprising that the relationship between reflective activities, necessary processes for individual learning, and employee creativity remains so poorly understood.

The purpose of this study was to examine the mediating effect of individual reflection on the relationship between team unlearning and employee creativity. The article is organized as follows: First, the literature on employee creativity, unlearning, and reflection is briefly reviewed, leading to the proposal of several hypotheses. Next, the methodological approach for testing the hypotheses is described. Finally, findings are presented and discussed from both theoretical and practical perspectives.

\section{Theoretical background and hypotheses}

\section{Employee creativity}

Employee creativity is defined as the production of novel and useful ideas by an individual (Amabile, 1988). The novel and useful ideas proposed by employees may 
increase the likelihood that other members will apply and develop them in their own work, subsequently transferring them to other members within the organization (Shalley et al., 2004). Therefore, it may be said that innovation and the success of a new product begin with the creative ideas conceived by a person or a team (Amabile, 1988; Amabile et al., 1996).

According to a comprehensive theory of creativity, which integrates intrinsic motivation and social environment with cognitive and personality constructs (Amabile and Pillemer, 2012), employee creativity is influenced by intra-individual components (e.g. expertise, cognitive style, personality and intrinsic task motivation) and social-environmental forces (e.g. team learning context). Prior research on intra-individual factors has reported that employee creativity was influenced by feedback-seeking (De Stobbeleir et al., 2011), creative personality (Dul et al., 2011), proactive personality (Kim et al., 2009), creative self-efficacy (Gong et al., 2009), psychological empowerment (Sun et al., 2012), learning orientation (Gong et al., 2009; Hirst et al., 2009) and intrinsic motivation (Tierney et al., 1999). These results suggest that individual personality, goals and psychological ormotivational states all affect creativity.

Regarding socio-environmental factors, it has been found that employee creativity is enhanced through transformational leadership (Gong et al., 2009), empowering leadership (Zhang and Bartol, 2010), team-learning behavior (Hirst et al., 2009), group-innovation climate (Wang et al., 2013), emotional and informational support (Madjar, 2008) and structural empowerment (Sun et al., 2012). Additionally, human resource practices, such as hiring, selection, job design, reward and social-organizational work environment, have been shown to promote employee creativity (Dul et al., 2011; Jiang et al., 2012; Sue-Chan and Hempel, 2016). These findings indicate that leadership, climate and practices experienced by the team or organization all affect employee creativity. Many studies have reported that intraindividual factors mediated ormoderated between socio-environmental factors and employee creativity (Gong et al., 2009; Madjar, 2008; Sun et al., 2012; Zhang and Bartol, 2010).

It is important to note that individuals can adapt their thinking and perspectives when they encounter any interruption to their habitual routines (Nonaka and Takeuchi, 1995). Previous studies suggest that disorienting dilemmas (Mezirow, 1990, 1997), interruptive events (Zellmer-Bruhn, 2003) and interfering events (Oertel and Antoni, 2014) can promote individual learning through reflective activities. Based on these arguments, this study focused on the role of unlearning within the team with regard to 
enhancing employee creativity, an aspect which has been overlooked in previous research.

\section{Team unlearning}

The concept of unlearning has been explored for more than 30 years in the context of organizational learning (Brook et al., 2016). In previous studies, unlearning, defined as the process of clearing out old routines and beliefs that no longer meet current challenges (Tsang and Zahra, 2008), has been demonstrated to be important for acquiring new knowledge. That is, an inability to discard outdated knowledge may become a major hindrance to learning or innovation (Easterby-Smith et al., 2004; Wang and Ahmed, 2003).

The process of organizational unlearning involves the evolution of individual and group unlearning (Zhao et al., 2013). To understand the role of unlearning processes within an organization, it is necessary to investigate unlearning at not only the organizational level but also the individual and team levels. However, little empirical research has examined unlearning at the individual or team levels, compared with the organizational level (Hislop et al., 2014). An exception is Akgun et al. (2006), whose study defined team unlearning as changes in beliefs and routines among teams, based on Nonaka et al. (2001) and Sinkula (2002). They conducted research surveys among teams developing new products and found that team unlearning positively influenced information-knowledge implementation and the likelihood of a new product's success. Following Akgun et al.'s (2006) conceptualization and measurement scale, Lee and Sukoco (2011) also reported that team reflexivity promoted team unlearning, resulting in team innovation. Considering that the success of a new product or team innovation begins with team members' creativity (Amabile, 1988; Amabile et al., 1996), it is envisioned that team unlearning will exert a positive influence on employee creativity.

To clarify the concept of unlearning, it is necessary to distinguish between team learning and team unlearning. In previous studies, team learning was conceptualized as the collective acquisition, combination, creation and sharing of knowledge by asking questions, seeking feedback, experimenting, reflecting on results and discussing errors (Argote, 1999; Edmondson, 1999; Ely et al., 2012; Zellmer-Bruhn and Gibson, 2006). This conceptualization suggests that team learning includes team unlearning, yet they are not identical concepts. That is, team learning exercises in which new knowledge or routines are acquired may be successful without the abandonment of existing knowledge or routines. Therefore, it may be said that team unlearning constitutes a particular type of team learning. In line with West's (2000) differentiation between 
"shallow reflection”, “moderate reflection” and “deep reflection”, team unlearning may occur through deep reflection, during which team members assimilate new awareness and learn at a meta-level.

To measure team unlearning, this study adopted the scale of Akgun et al. (2006). However, two problems impair the optimization of this scale. First, the scale of team unlearning only measures changes in beliefs and routines within teams, but does not consider "the abandonment of outdated beliefs and routines". It may be possible to acquire new beliefs and routines without altering or abandoning existing practices. For example, a team may modify its routine simply by introducing new software, without changing any existing work procedures. Thus, the present research defined and operationalized team unlearning as the practice of changing beliefs and work routines by abandoning outdated, obsolete ones.

Second, Akgun et al. (2006) did not examine the effect of team unlearning on intraindividual components of creativity. To understand how team unlearning promotes creativity in teams, it is important to investigate the influence of team unlearning on individual creativity. This study focused on the mediating role of individual reflection in bridging team unlearning and individual creativity.

\section{Individual reflection}

For the purpose of this study, individual reflection was defined as the extent to which an individual periodically reviews his or her work objectives and methods, based on West's (2000) work on individual reflexivity. As reflexivity often refers to critical reflection, by which individuals examine and question their fundamental assumptions or deeply held values (Cunliffe, 2009; Cunliffe and Easterby-Smith, 2004; Tams and Marshall, 2011), the present research used the term "individual reflection" rather than "individual reflexivity".

Prior studies reported that reflection or reflexivity at the group level had a positive influence on learning and performance (Dayan and Basarir, 2010; Gurtner, Tschan, Semmer, and Nagele, 2007; Schippers, Homan, and van Knippenberg, 2013), but quantitative research on individual reflection is limited (Toy et al., 2009). According to Kolb's (1984) experiential learning model, reflection on work experience is a necessary step for acquiring knowledge and skills through experience as part of an employee's growth. Nilsen et al. (2012) also stated that reflection is a mechanism for translating experience into learning, through examining one's attitudes, beliefs and actions, to facilitate better choices or responses in the future. Despite their close relationships, no previously reported research has investigated the relationships between 
team unlearning, individual reflection and employee creativity.

Nonaka and Takeuchi (1995) stated that individuals have an opportunity to reconsider their fundamental thinking and perspectives if they encounter any interruption to their habitual and comfortable states of being. Mezirow $(1990,1997)$ also indicated that triggering events, such as a disorienting dilemma, can lead individuals to engage in critical reflection. Such triggering events may include any form of work contingency or predicament over decision-making processes. Similarly, it has been reported that interruptive events (Zellmer- Bruhn, 2003) or interfering events (Oertel and Antoni, 2014) play important roles in facilitating reflection and learning among the team. As mental conceptualizations of the key elements at play within a team are common to its members (Mohammed et al., 2010), the transformation of shared, habitual beliefs and routines within a team can be a triggering event for individual team members, prompting them to reflect on their own work styles and practices. For example, conflicts around problem solving within a team have been shown to induce reflection among its members (Shirouzu et al., 2002). Thus, team unlearning may inspire members to reevaluate the validity and appropriateness of their work processes, and to search for new ones. Accordingly, the following hypothesis is proposed:

H1. Team unlearning is positively related to individual reflection.

To conceive new and useful ideas, individuals need to think to identify problems and solutions by reflecting on their objectives and work processes. At the group level, a positive relationship between reflection and innovation in teams has been reported (Farnese and Livi, 2016; Widmann et al., 2016), but the reflection-creativity relationship has not been investigated at the individual level, except for the study conducted by Messmann and Mulder (2015). They reported that work-related reflection was positively associated with innovative work behavior, interpreting this finding as an indication that reflection provides employees with the flexibility that allows them to adopt innovative approaches, particularly when tasks are unfamiliar or ambiguous. Conceptually, several authors have stressed the role of reflection in enhancing individual learning. For example, Kolb’s (1984) experiential learning theory suggested that reflection on our experiences is a significant step in acquiring new knowledge and skills. Schön (1983) also stated that professional practitioners solve problems through reflection in action. Similarly, Mezirow (1997) argued that self-reflection can lead to transformative learning, or the process of effecting change in a frame of reference. These arguments suggest that individual reflection promotes creativity by extracting 
lessons from experience, solving problems and changing one's frame of reference. Thus, the following hypothesis is proposed:

H2. Individual reflection is positively related to employee creativity.

It is also believed that team unlearning directly influences employee creativity, and previous studies have reported that socio-environmental factors impact employee creativity. For example, Wang et al. (2013) found that group-innovation climate mediated the relationship between transformational leadership and employee creativity. When routines and beliefs change at team level, members may be compelled to adapt their modes of thinking and their behaviors. Sinkula (2002) argued that organizational routines and beliefs influence individual stimulus-response learning. Feldman (2000) also stated that changes to the habitual routines of a group direct the members' attention toward group norms. Based on these arguments, it seems likely that team unlearning directly promotes employee creativity. As such, the following hypothesis is proposed:

H3. Team unlearning is positively related to employee creativity.

Combining $\mathrm{H} 1$ and $\mathrm{H} 2$ suggests that team unlearning has an indirect effect on employee creativity through individual reflection. The rationale for this relationship is that interruption of a habitual and comfortable state of being, due to changing routines and beliefs within the team, may prompt members to reconsider and review their own perspectives and work practices (Nonaka and Takeuchi, 1995). Meanwhile, reflection offers a key pathway for identifying and solving problems (Schön, 1983), by which individuals acquire new and useful ideas for application to work processes. Furthermore, as team unlearning has been shown to promote the success of a new product (Akgun et al., 2006) and team innovation (Lee and Sukoco, 2011), it is predicted that team unlearning will have a positive influence on employee creativity through individual reflection. Considering H3, which envisions a direct influence exerted on employee creativity by team unlearning, the mediation effect of individual reflection between team unlearning and employee creativity is partial rather than full. The partial mediation model differs from the full (complete) mediation model by adding a direct effect from $\mathrm{X}$ (independent variable) to Y (dependent variable) (James et al., 2006; Shrout and Bolger, 2002). As suggested above, changing routines and beliefs may directly enhance employee creativity through normative or motivational influence. Thus, the following mediating hypothesis is proposed: 
H4. Individual reflection partially mediates the relationship between team unlearning and employee creativity.

Based on H4, this study proposed the conceptual framework shown in Figure 1. The present research investigates the process by which team unlearning enhances employee creativity, directly or indirectly, through individual reflection.

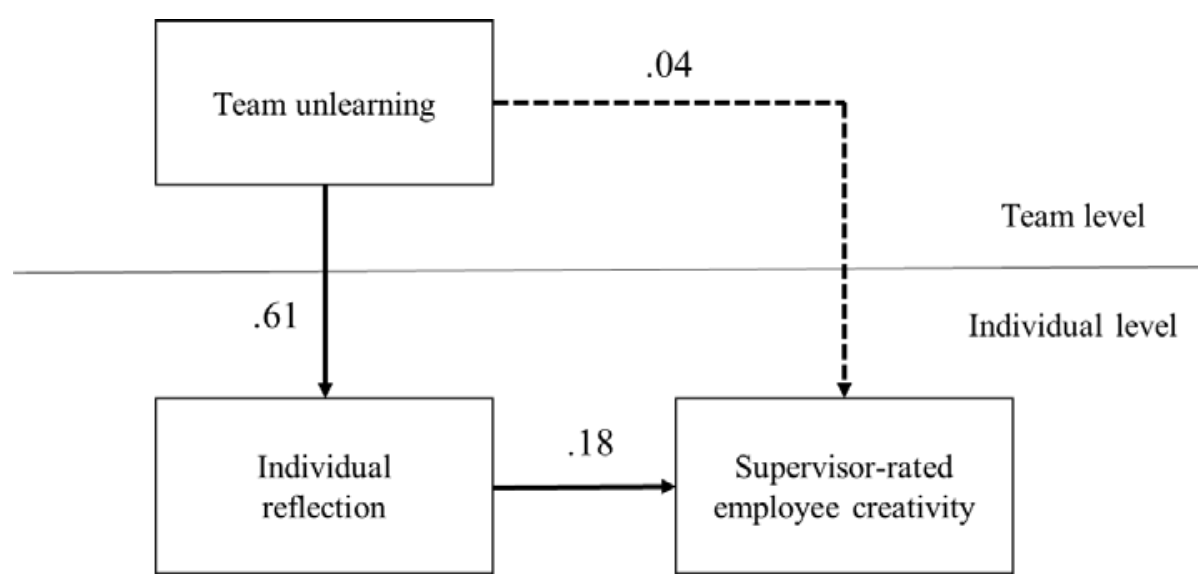

Note: The figures are estimates. The effects of gender and team size were controlled. The dotted line means non-significant path.

Figure 1. Conceptual framework

\section{Method}

\section{Participants and procedures}

The participants were employees working in the $R \& D$ department of a Japanese manufacturing firm and the telemarketing department of a Japanese service firm. An advantage of this sampling is that the results can be generalized to diverse work settings. Specifically, engineers from the manufacturing firm were engaged in developing new technologies and products, while employees from the service firm had roles supervising temporary workers (operators). Both sets of subjects needed to unlearn their knowledge and skills to adjust to changing technologies and client needs. By analyzing data from different employee types, it may be possible to obtain results that can be applied to a variety of work settings.

Questionnaires were distributed to 309 staff level employees (103 at the 
manufacturing firm 206 at the service firm) and their supervisors, using a web-based survey system operated by the individual firms. In total, 164 questionnaires (95 at the manufacturing firm, 69 at the service firm) from 28 teams (16 at the manufacturing firm, 12 at the service firm) were deemed usable after removing inappropriate answers. The final survey response rate was 53.1 per cent (92.2 per cent at the manufacturing firm, 33.5 per cent at the service firm). The high response rate at the manufacturing firm is likely to be because of its traditional, strict Japanese management style in which engineers tend to follow orders from their managers. The average team size (i.e. the number of respondents) was 5.85 (standard deviation, $\mathrm{SD}=4.60$ ). The sample was 67.7 per cent male.

\section{Measures}

Team unlearning was assessed using a six-item modified version of the scale of Akgun et al. (2006), which was developed for a new product development project team. Respondents were asked about the extent to which their team had recently changed their beliefs, work routines or processes by abandoning obsolete, outdated practices. Changes in beliefs relating to the following areas were addressed: "beliefs regarding technological improvements", "beliefs regarding the external environment" and "beliefs regarding customer demand". Changes in routines related to the following were addressed: "work methods or procedures," "methods for gathering and sharing information" and "decision-making processes or methods." Items were rated on a five-point scale ( $1=$ not at all, $5=$ a lot; $\mathrm{a}=0.87$ ), and average scores for the items were used in the analyses.

Individual reflection was assessed using the five-item scale developed by West (2000) for measuring individual level reflection. The items were "I often review my work objectives", "I often reflect upon whether I am working effectively", "I often review the methods I use to get the job done”, "I modify my work objectives in the light of changing circumstances at work" and "I often review my approach to getting the job done”. Each item measured reflection on a five-point Likert scale ( 1 = strongly disagree, 5 = strongly agree; $a=0.89$ ). Average scores of the items were used in the analyses.

Employee creativity was assessed using the nine-item scale developed by Tierney et al. (1999). Supervisors were asked to evaluate their subordinates' creativity. Sample items included "Demonstrated originality in his/her work," and "Served as a good role model for creativity." Each item measured creativity on a five-point Likert scale $(1=$ strongly disagree, $5=$ strongly agree; a $=0.93)$. Average scores of the items were used in the analyses. 
As control variables, dichotomous dummy variables for gender $(1=$ female, 2 $=$ males) and team size (the number of members) were included in the equation.

\section{Analyses}

To assess consensus regarding team unlearning among team members, the intraclass correlation coefficient rwg(j) and interclass correlation coefficients (ICC1 and ICC2) were calculated. The rwg(j), ICC1 and ICC2 values were 0.85, 0.23 and 0.73, respectively. Although there is no consensus on clear cutoff levels in past studies, these scores were greater than the traditional cutoff criteria of 0.70, 0.12 and 0.50 (George, 1990; James, 1982; LeBreton and Senter, 2008), suggesting that the team members had relatively uniform perceptions of team unlearning.

To evaluate the convergent validity of the model constructs, a confirmatory factor analysis (CFA) was conducted with three latent learning constructs (team unlearning, individual reflection, and employee creativity) and 16 items (team unlearning consisted of two average scores: belief changes and routine changes). The results showed that all items loaded significantly on the respective constructs. The goodness-of-fit statistics for the model were as follows: comparative fit index (CFI) = 0.92, Tucker-Lewis Index $(\mathrm{TLI})=0.91$, standardized root mean square residual $(\mathrm{SRMR})=0.07$ and root-mean-square error of approximation $(\mathrm{RMSEA})=0.08$. Considering the cutoff criteria proposed in previous studies, the fit indices of the model were acceptable. Additionally, Table I shows that the three-factor model fit the data much better than the single- and two-factor models. This indicates that the influence of common method bias was minimized in this study (Podsakoff et al., 2003). Convergent validities of the factors were also estimated in terms of the average variance extracted (AVE). Because the AVEs in all estimates were above the recommended limit of 0.50 (Table II), the scores were acceptable. Finally, Cronbach's alpha values for all the scales were above 0.70 (Table II), showing that the scores met the recommended reliability coefficient of 0.70 (Nunnally, 1978).

To test the mediating effect of individual reflection on the relationship between team unlearning and employee creativity, the indirect effect was calculated and subjected to both the Sobel test (Sobel, 1982) and the Aroian test (Aroian, 1947), commonly used procedures for evaluating the strength of mediation effects (MacKinnon et al., 2002). Additionally, the mediation effect type was assessed based on Shrout and Bolger (2002). Specifically, the effect of team unlearning on employee creativity is partially mediated by individual reflection, when the mediating effect of individual 
reflection on the relationship between team unlearning and employee creativity is significant. The bridge between team unlearning and employee creativity is also significant. When the mediating effect of individual reflection on the relationship between team unlearning and employee creativity is significant, but team unlearning exerts no direct influence on employee creativity, individual reflection fully mediates between team unlearning and employee creativity.

Table I. CFA results of measurement models

\begin{tabular}{ccccccc}
\hline Model & $\chi 2$ & $d f$ & CFI & TLI & SRMR & RMSEA \\
\hline Three-factor model & 225.27 & 101 & .92 & .91 & .07 & .08 \\
Two-factor model & 296.25 & 103 & .88 & .86 & .08 & .10 \\
One-factor model & 728.25 & 104 & .62 & .56 & .18 & .19 \\
\hline
\end{tabular}

Note: $\mathrm{N}=164$. Three-factor model: Each variable was loaded on a single factor; Two-factor model: Individual creativity and individual reflection were loaded on one factor; One-factor: all variables were loaded on a single factor.

Table II. Means, standard deviations, reliabilities and correlations of individual level data $(\mathrm{N}=164$, level1; $\mathrm{k}=28$, level 2)

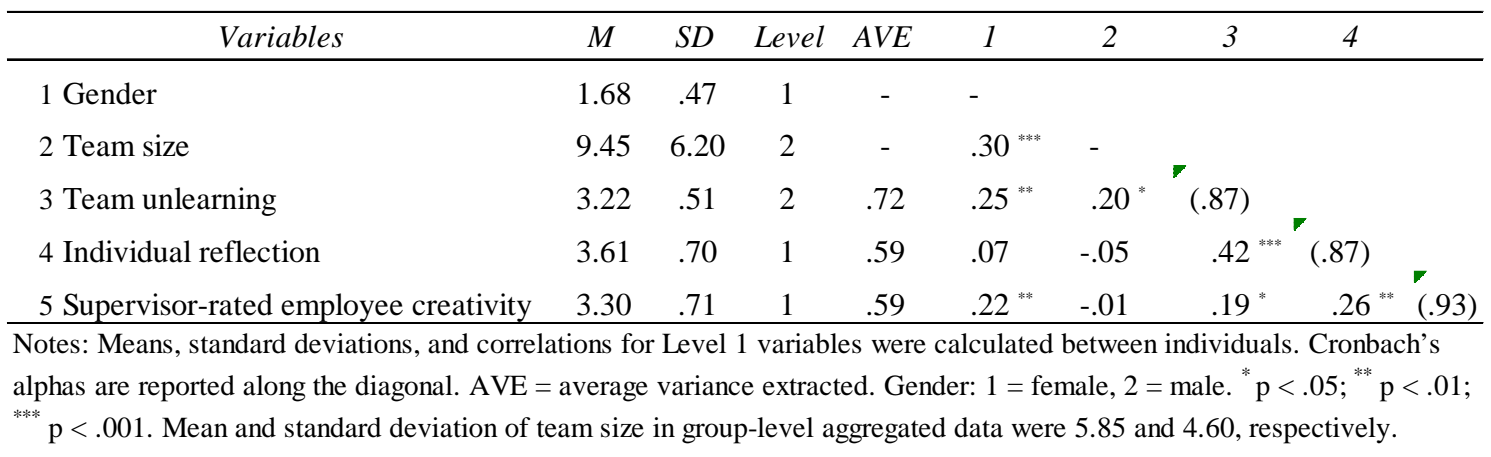

\section{Results}

The means, standard deviations and inter-correlations of the variables are presented in Table II. To test the hypotheses, multilevel analyses (hierarchical linear modeling analyses) were conducted (Table III). All variables examined in the analyses were grand-mean centered. The results show that team unlearning was positively related to individual reflection ( $\mathrm{g}=0.61, \mathrm{p}<0.001$ ). The high score may not be because of common method bias, because there was a moderate correlation between the variables ( $\mathrm{r}$ $=0.42$; Table I). The results also indicated that individual reflection was positively related to employee creativity ( $g=0.18, \mathrm{p}<0.05$ ), supporting $\mathrm{H} 2$. However, team unlearning was not significantly related to employee creativity ( $g=0.04$, ns), indicating that $\mathrm{H} 3$ was not supported. Regarding $\mathrm{H} 4$, assuming the partial mediation effect of 
individual reflection between team unlearning and employee creativity, the indirect effect of team unlearning on employee creativity through individual reflection was significant $(0.13, \mathrm{p}<0.001)$. The results of the Sobel and Aroian tests were also significant $(2.08, \mathrm{p}<0.05 ; 2.06, \mathrm{p}<0.05)$. Considering that no direct, significant relationship between team unlearning and employee creativity was identified, it may be said that individual reflection fully mediates the relationship between team unlearning and employee creativity. Thus, H4 was partially supported.

Table III. Results of hierarchical linear modeling analyses $(\mathrm{N}=164 ; \mathrm{k}=28)$

\begin{tabular}{lcc}
\hline \multicolumn{1}{c}{ Variable } & $\begin{array}{c}\text { Individual } \\
\text { reflection }\end{array}$ & $\begin{array}{c}\text { Supervisor-rated } \\
\text { employee } \\
\text { creativity }\end{array}$ \\
\hline $\begin{array}{l}\text { Team level predictors } \\
\text { Team unlearning }\end{array}$ & $\gamma(\mathrm{SE})$ & $\gamma(\mathrm{SE})$ \\
$\begin{array}{l}\text { Individual level predictors } \\
\text { Individual reflection }\end{array}$ & $.61(.11)^{* * *}$ & $.04(.17)$ \\
$\begin{array}{l}\text { Control variables } \\
\text { Gender } \\
\text { Team size }\end{array}$ & & $.18(.08)^{*}$ \\
\hline
\end{tabular}

Notes: ${ }^{*} \mathrm{p}<.05 ;{ }^{* *} \mathrm{p}<.01 ;{ }^{* * *} \mathrm{p}<.001$

\section{Discussion}

The enhancement of employee creativity has been an important issue in HRM (Dul et al., 2011; Sue-Chan and Hempel, 2016). Although unlearning is considered an essential process for creativity, little is known about the relationship between unlearning and employee creativity. The results of multilevel analyses of multisource survey data suggest that team unlearning enhances employee creativity, mediated through individual reflection.

\section{Theoretical implications}

This study contributes theoretically to existing research on both team learning and HRM. First, the present research clarified the mechanisms by which team unlearning promotes employee creativity. Although team unlearning is closely related to product success and innovation within teams, only limited empirical research has been reported (Akgun et 
al., 2006; Lee and Sukoco, 2011). This article may be the first study to reveal a process relating to how team unlearning influences employee creativity. Although prior studies reported that team unlearning had an impact on new product success (Akgun et al., 2006) and product innovation (Lee and Sukoco, 2011), the results of this study indicate the necessity of acknowledging individual learning processes when investigating the effect of team unlearning on team performance. This study complements the existing literature by identifying the mechanisms, whereby unlearning enhances creativity in teams.

Second, the findings showed that individual reflection plays an important role in linking team unlearning and employee creativity. It should be noted that team unlearning had no direct impact on employee creativity. These results are consistent with the arguments of Boud et al. (2006); Kolb (1984) and Schön (1983), which posit that reflection is key to learning and fostering positive occupational outcomes. The findings suggest that employee creativity is not automatically inspired by team unlearning, by means of stimulus-response learning, but that it is the outcome of reflective activities.

Third, prior research on HRM has reported that HR practices, such as rewarding creativity and designing social-organizational work environments, have a positive influence on employee creativity (Dul et al., 2011; Sue-Chan and Hempel, 2016). It may be that individual reflection mediates the relationship between such HR practices and employee creativity. Specifically, some types of reward systems or work environments may encourage employees to review their work processes for more creative outcomes.

Fourth, it is important to note that organization type as a control variable had a strong effect on employee creativity. This is because the average score of employee creativity was higher in the $R \& D$ department of the manufacturing firm $(M=3.86)$ than in the telemarketing department of the service firm $(M=3.30)$. The results suggest that the findings described above can be generalized for diverse organizations, in which different levels of creativity are required for different employees.

\section{Practical implications}

The present research has managerial implications for HR managers who wish to promote employee creativity. First, HR managers must recognize that a team's abandonment of obsolete beliefs and routines not only promotes team innovation but also individual creativity. Therefore, it is important to provide team leaders with opportunities to examine whether existing practices and beliefs work within the teams. 
If these practices or beliefs become outdated, HR managers should allow team leaders to transform, update and refine them. A feedback system using a questionnaire survey for team members may be effective for alerting managers about the need to change obsolete, habitual routines in the workplace. Training programs are also necessary to help managers understand the importance of unlearning in operating teams.

Second, it should be noted that employee creativity is not automatically promoted by team unlearning. To facilitate employee creativity, team leaders should encourage members to reflect on their objectives and work processes by asking appropriate questions. Thus, HR managers must introduce practices of periodically reviewing obsolete beliefs and work routines for team leaders and members to promote their creativity. "After event review”, which refers to a learning procedure that gives learners an opportunity to systematically analyze their behavior (DeRue et al., 2012), may be useful for facilitating unlearning and reflection in teams.

\section{Limitations and future research}

This study has some limitations. First, survey data were collected only from Japanese organizations, so national culture may have affected the results. Although the role of industry was diminished by including a manufacturer and a service organization in the sample, future research should analyze data from other countries and industries to generalize the findings.

Second, although the small sample size at level 2 did not lead to biased estimates of the regression coefficients (Maas and Hox, 2005), it would be desirable to increase the sample size to obtain more reliable results in future research.

Third, this study measured unlearning at the team level, but did not measure unlearning at the individual level. It would be interesting to include individual unlearning in the model to examine how team unlearning facilitates individual unlearning, resulting in individual creativity.

Fourth, it is possible that the enhancement of employee creativity through team unlearning and individual reflection may lead to changes in work routines. Future research should apply a model that bridges employee creativity and team unlearning.

Fifth, this study is based on cross-sectional survey data, although multilevel analysis and multi-source data were used. Replications of the research model should use longitudinal survey data.

Finally, it may be worthwhile to examine the effects of HR practices on team unlearning, individual reflection and creativity in future research. 
Funding: This work was supported by JSPS KAKENHI [grant number 26285078].

\section{References}

Akgun, A.E., Lynn, G.S. and Byrne, J.C. (2006), “Antecedents and consequences of unlearning in new product development teams”, Journal of Product Innovation Management, Vol. 23 No. 1, pp. 73-88.

Amabile, T.M. (1988), “A model of creativity and innovation in organizations”, in Staw, B.M. and Cummings, L.L. (Eds), Research in Organizational Behavior, 10, JAI press, Greenwich, CT, pp. 123-167.

Amabile, T.M. and Pillemer, J. (2012), "Perspectives on the social psychology of creativity”, Journal of Creative Behavior, Vol. 46 No. 1, pp. 3-15.

Amabile, T.M., Conti, R., Coon, H., Lazenby, J. and Herron, M. (1996), “Assessing the work environment for creativity”, Academy of Management Journal, Vol. 39, pp. 1154-1184.

Argote, L. (1999), Organizational Learning: Creating, Retaining, and Transferring Knowledge, Norwell, MA: Kluwer Academic.

Aroian, L.A. (1947), "The probability function of the product of two normally distributed variables”, Annals of Mathematical Statistics, Vol. 18 No. 2, pp. 265-271.

Boud, D., Cressery, P. and Docherty, P. (2006), "Setting the scene for productive reflection”, in Boud, D. Cressery, P. and Docherty P. (Eds), Productive Reflection at Work: Learning for Changing Organizations, Routledge, Oxon, pp. 3-10.

Brook, C., Pedler, M., Abbott, C. and Burgoyne, J. (2016), “On stopping doing those things that are not getting us to where we want to be: unlearning, wicked problems and critical action learning”, Human Relations, Vol. 69 No. 2, pp. 369-389.

Clercq, D., Rahman, Z.M. and Belausteguigoitia, I. (2017), “Task conflict and employee creativity: the critical roles of learning orientation and goal congruence”, Human Resource Management, Vol. 56 No. 1, pp. 93-109.

Cunliffe, A.L. (2009), “The philosopher leader: on relationalism, ethics and reflexivity a critical perspective to teaching leadership”, Management Learning, Vol. 40 No. 1, pp. 87-101.

Cunliffe, A.L. and Easterby-Smith, M. (2004), "From reflection to practical reflexivity: experiential learning as lived experience”, in Reynolds, M. and Vince, R. (Eds), Organizing Reflection, Ashgate/Gower, Aldershot, pp. 30-46.

Dayan, M. and Basarir, A. (2010), “Antecedents and consequences of team reflexivity in new product development projects”, Journal of Business and Industrial Marketing, 
Vol. 25 No. 1, pp. 18-29.

De Stobbeleir, K.A., Ashford, S.J. and Buyens, D. (2011), "Self-regulation of creativity at work: the role of feedback-seeking behavior in creative performance”, Academy of Management Journal, Vol. 54 No. 4, pp. 811-831.

DeRue, D.S., Nahrgang, J.D., Hollenbeck, J.R. and Workman, K. (2012), “A quasi-experimental study of after-event reviews and leadership development”, Journal of Applied Psychology, Vol. 97 No. 5, pp. 997-1015.

Dul, J., Ceylan, C. and Jaspers, F. (2011), “Knowledge workers' creativity and the role of the physical work environment”, Human Resource Management, Vol. 50 No. 6, pp. 715-734.

Easterby-Smith, M., Antonacopoulou, E., Simm, D. and Lyles, M. (2004), "Constructing contributions to organizational learning: Argyris and the next generation”, Management Learning, Vol. 35 No. 4, pp. 371-380.

Edmondson, A. (1999), "Psychological safety and learning behavior in work teams", Administrative Science Quarterly, Vol. 44 No. 2, pp. 350-383.

Edmondson, A.C., Bohmer, R.M. and Pisano, G.P. (2001), "Disrupted routines: team learning and new technology implementation in hospitals”, Administrative Science Quarterly, Vol. 46 No. 4, pp. 685-716.

Ely, R.J., Padavic, I. and Thomas, D.A. (2012), "Radical diversity, radical asymmetries, and team learning environment: effects on performance”, Organization Studies, Vol. 33 No. 3, pp. 341- 362.

Farh, J., Lee, C. and Farh, C.I.C. (2010), “Task conflict and team creativity: a question of how much and when”, Journal of Applied Psychology, Vol. 95 No. 6, pp. 1173-1180.

Farnese, M.L. and Livi, S. (2016), “How reflexivity enhances organizational innovativeness: the mediation role of team support for innovation and individual commitment”, Knowledge Management Research and Practice, Vol. 14 No. 4, pp. 525-536.

Feldman, M.S. (2000), “Organizational routines as a source of continuous change”, Organization Science, Vol. 11 No. 6, pp. 611-629.

George, J.M. (1990), “Personality, affect, and behavior in groups”, Journal of Applied Psychology, Vol. 75 No. 2, pp. 107-116.

Gong, Y., Huang, J. and Farh, J. (2009), “Employee learning orientation, transformational leadership, and employee creativity: the mediating role of employee creative self-efficacy”, Academy of Management Journal, Vol. 52 No. 4, pp. $765-778$. 
Gurtner, A., Tschan, F., Semmer, N.K. and Nagele, C. (2007), “Getting groups to develop good strategies: effects of reflexivity interventions on team process, team performance, and shared mental models”, Organizational Behavior and Human Decision Processes, Vol. 102 No. 2, pp. 127-142.

Hirst, G., Van Knippenberg, D. and Zhou, J. (2009), “A cross-level perspective on employee creativity: goal orientation, team learning behavior, and individual creativity”, Academy of Management Journal, Vol. 52 No. 2, pp. 280-293.

Hirst, G., Van Knippenberg, D., Zhou, J., Quintane, E. and Zhu, C. (2015), “Heard it through the grapevine: indirect networks and employee creativity”, Journal of Applied Psychology, Vol. 100 No. 2, pp. 567-574.

Hislop, D., Bosley, S., Coombs, C.R. and Holland, J. (2014), “The process of individual unlearning: a neglected topic in an under-researched field”, Management Learning, Vol. 45 No. 5, pp. 540-560.

James, L.R. (1982), “Aggregation bias in estimates of perceptual agreement”, Journal of Applied Psychology, Vol. 67 No. 2, pp. 219-229.

James, L.R., Mulaik, S.A. and Brett, J.M. (2006), “A tale of two methods", Organizational Research Methods, Vol. 9 No. 2, pp. 233-244.

Jiang, J., Wang, S. and Zhao, S. (2012), “Does HRM facilitate employee creativity and organizational innovation? A study of Chinese firms”, International Journal of Human Resource Management, Vol. 23 No. 19, pp. 4025-4047.

Keskin, H. (2006), "Market orientation, learning orientation, and innovation capabilities in SMEs: an extended model”, European Journal of Innovation Management, Vol. 9 No. 4, pp. 396-417.

Kim, T., Hon, A.H.Y. and Crant, J.M. (2009), "Proactive personality, employee creativity, and newcomer outcomes: a longitudinal study”, Journal of Business and Psychology, Vol. 24 No. 1, pp. 93-103.

Kolb, D.A. (1984), Experiential Learning: Experience as the Source of Learning and Development, Prentice-Hall, NJ.

LeBreton, J.M. and Senter, J.L. (2008), “Answers to 20 questions about interrater reliability and interrater agreement”, Organizational Research Methods, Vol. 11 No. 4, pp. 815-852.

Lee, L.T. and Sukoco, B.M. (2011), "Reflexivity, stress, and unlearning in the new product development team: The moderating effect of procedural justice”, $R \& D$ Management, Vol. 41, pp. 410-423.

MacKinnon, D.P., Lockwood, C.M., Hoffman, J.M., West, S.G. and Sheets, V. (2002), "A comparison of methods to test mediation and other intervening variable effects", 
Psychological Methods, Vol. 7 No. 1, pp. 83-104.

Maas, C.J.M. and Hox, J.J. (2005), "Sufficient sample size for multilevel modeling”, Methodology, Vol. 1 No. 3, pp. 86-92.

Madjar, N. (2008), "Emotional and informational support from different sources and employee creativity”, Journal of Occupational and Organizational Psychology, Vol. 81 No. 1, pp. 83-100.

Messmann, G. and Mulder, R.H. (2015), "Reflection as a facilitator of teachers' innovative work behavior”, International Journal of Training and Development, Vol. 19 No. 2, pp. 125-137.

Mezirow, J. (1990), "How critical reflection triggers transformative learning”, in Mezirow, J. and Associates (Eds), Fostering Critical Reflection in Adulthood: A Guide to Transformative and Emancipatory Learning, Jossey-Bass, San Francisco, pp. 1-20.

Mezirow, J. (1997), “Transformative learning: theory to practice”, New Directions for Adult and Continuing Education, Vol. 1997 No. 74, pp. 5-12.

Mohammed, S., Ferzandi, L. and Hamilton, K. (2010), "Metaphor no more: a 15-year review of the team mental model construct”, Journal of Management, Vol. 36 No. 4, pp. 876-910.

Nilsen, P., Nordstrom, G. and Ellstrom, P. (2012), "Integrating research-based and practice-based knowledge through workplace reflection”, Journal of Workplace Learning, Vol. 24No. 6, pp. 403-415.

Nonaka, I. and Takeuchi, H. (1995), The Knowledge-Creating Company, Oxford, New York, NY.

Nonaka, I., Toyoma, R. and Byosiere, P. (2001), “A theory of organizational knowledge creation: understanding the dynamic process of creating knowledge”, in Dierkes, M. (Eds), Handbook of Organizational Learning and Knowledge, Oxford University Press, New York, NY, pp. 491-518.

Nunnally, J.C. (1978), Psychometric Theory, (2nd ed), McGraw-Hill, New York, NY.

Oertel, R. and Antoni, C.H. (2014), "Reflective team learning: linking interfering events and team adaptation”, Team Performance Management: An International Journal, Vol. 20 Nos 7/8, pp. 328-342.

Podsakoff, P.M., MacKenzie, S.B., Lee, J. and Podsakoff, N.P. (2003), “Common method biases in behavioral research: a critical review of the literature and recommended remedies”, Journal of Applied Psychology, Vol. 88 No. 5, pp. 879-903.

Schön, D.A. (1983), The Reflective Practitioner, How Professionals Think in Action, 
Basic books, New York, NY.

Shalley, C.E., Zhou, J. and Oldham, G.R. (2004), "The effects of personal and contextual characteristics on creativity: where should go from here?”, Journal of Management, Vol. 30 No. 6, pp. 933-958.

Schippers, M.C., Homan, A.C. and Van Knippenberg, D. (2013), “To reflect or not to reflect: Prior team performance as a boundary condition of the effects of reflexivity on learning and final team performance", Journal of Organizational Behavior, Vol. 34, pp. 6-23.

Shirouzu, H., Miyake, N. and Masukawa, H. (2002), “Cognitively active externalization for situated reflection”, Cognitive Science, Vol. 26 No. 4, pp. 469-501.

Shrout, P.E. and Bolger, N. (2002), "Mediation in experimental and nonexperimental studies: new procedures and recommendations”, Psychological Methods, Vol. 7 No. 4, pp. 422-445.

Sinkula, J.M. (2002), “Market-based success, organizational routines, and unlearning”, Journal of Business and Industrial Marketing, Vol. 17 No. 4, pp. 253-260.

Sobel, M.E. (1982), “Asymptotic confidence intervals for indirect effects in structural equation models”, in Leinhardt S. (Ed.), Sociological Methodology, Jossey-Bass, San Francisco, pp. 290-312.

Sue-Chan, C. and Hempel, P.S. (2016), “The creativity-performance relationship: how rewarding creativity moderates the expression of creativity”, Human Resource Management, Vol. 55 No. 4, pp. 637-653.

Sun, L., Zhang, Z., Qi, J. and Chen, Z.X. (2012), "Empowerment and creativity: a cross-level investigation”, Leadership Quarterly, Vol. 23 No. 1, pp. 55-65.

Tams, S. and Marshall, J. (2011), "Responsible careers: systemic reflexivity in shifting landscapes”, Human Relations, Vol. 64 No. 1, pp. 109-131.

Tierney, P., Farmer, S.M. and Graen, G.B. (1999), "An examination of leadership and employee creativity: the relevance of traits and relationships", Personnel Psychology, Vol. 52 No. 3, pp. 591-620.

Toy, E.C., Harms, K.P., Morris, R.K., Simmons, J.R., Kaplan, A.L. and Ownby, A.R. (2009), "The effect of monthly resident reflection on achieving rotation goals", Teaching and Learning in Medicine, Vol. 21 No. 1, pp. 15-19.

Tsang, E.W.K. and Zahra, S.A. (2008), “Organizational unlearning”, Human Relations, Vol. 61 No. 10, pp. 1435-1462.

Wang, C.L. and Ahmed, P.K. (2003), “Organizational learning: a critical review”, Learning Organization, Vol. 10 No. 1, pp. 8-17.

Wang, P., Rode, J.C., Shi, K., Luo, Z. and Chen, W. (2013), “A workgroup climate 
perspective on the relationships among transformational leadership, workgroup diversity, and employee creativity", Group and Organization Management, Vol. 38 No. 3, pp. 334-360.

West, M.A. (2000), "Reflexivity, revolution and innovation in work teams", in Beyerlein, M.M., Johnson D.A. and Beyerlein S.T. (Eds), Product Development Teams, JAI Press, Stamford CT, Vol. 5 pp. 1-29.

Widmann, A., Messmann, G. and Mulder, R.H. (2016), “The impact of team learning behaviors on team innovative work behavior: a systematic Review", Human Resource Development Review, Vol. 15 No. 4, pp. 429-458.

Zellmer-Bruhn, M.E. (2003), "Interruptive events and team knowledge acquisition”, Management Science, Vol. 49 No. 4, pp. 514-528.

Zellmer-Bruhn, M. and Gibson, C. (2006), "Multinational organizational context: implications for team learning and performance”, Academy of Management Journal, Vol. 49 No. 3, pp. 501-518.

Zhang, X. and Bartol, K.M. (2010), "Linking empowering leadership and employee creativity: the influence of psychological empowerment, intrinsic motivation, and creative process engagement”, Academy of Management Journal, Vol. 53 No. 1, pp. 107-128.

Zhao, Y., Lu, Y. and Wang, X. (2013), "Organizational unlearning and organizational relearning: a dynamic process of knowledge management”, Journal of Knowledge Management, Vol. 17 No. 6, pp. 902-912.

\section{Corresponding author}

Makoto Matsuo can be contacted at: mmatsuo@econ.hokudai.ac.jp 